Lumbar OP was associated with the female sex ( $\mathrm{OR}=3.6)$. The FN T-score (and, to a lesser extent, lumbar T-score), showed a correlation with age $(r=-0.515$, $\mathrm{p}<0.01$ ). No differences were found in the mean values of BMD, T-score y $Z$-score of FN and LS between positive or negative patients for FR or ACPA (t-student), neither between their possible combinations (one-way ANOVA). Association between positivity of RF, ACPA or their combinations and T-score <-1 (osteopenia) or T-score $<-2.5(\mathrm{OP})$ in LS or FN were not found. A negative weak correlation was found between the RF and lumbar BMD values $(-0.121, p=0.04)$ and $a$ positive weak correlation between ACPA and FN ( 0.136 with BMD, 0.131 with Tscore and 0138 with $Z$-score; $p<0.05$ for all).

\begin{tabular}{lccccc}
\hline & $\begin{array}{c}\text { Patients } \mathrm{n} \\
(\%)\end{array}$ & $\begin{array}{c}\text { BMD FN g/ } \\
\mathrm{cm}^{2} \\
\text { mean(SD) }\end{array}$ & $\begin{array}{c}\text { BMD LS g/ } \\
\mathrm{cm}^{2} \\
\text { mean(SD) }\end{array}$ & $\begin{array}{c}\text { T-score <- } \\
\mathrm{n}(\%)\end{array}$ & $\begin{array}{c}\text { T-score <- } \\
2,5\end{array}$ \\
$\mathrm{n}(\%)$
\end{tabular}

Conclusions: OP was very common in our RA population, especially in women and elderly. Any association was demonstrated between OP and the presence/ titer of autoantibodies (RF and ACPA) and low dose of corticosteroids treatment.

Disclosure of Interest: None declared

DOI: 10.1136/annrheumdis-2018-eular.5631

\section{AB1006 BONE STATUS OF PATIENTS TREATED WITH ANTI- AROMATASE: RESULTS AT ONE YEAR}

M. Djennane, C. Sedkaoui, F. Bouzar. Medecine, University of Medicine Mouloud Mammeri, Tizi Ouzou, Algeria

Background: First cancer in Algeria, first cause of cancer mortality in women. One in 10 women will develop breast cancer in her lifetime. Its incidence is increasing with 55.8/100000 inhabitants. The majority of these cancers are hormone-dependent. The bone loss induced by anti-aromatase (AA) leads to an increase in bone resorption with bone loss 2 to 4 times greater than the physiological loss.Randomised controlled trials (RCTs) including women under AA for 5 years have suggested an increased risk of fracture of $18 \%$ to $20 \%$ ie 1 in 5 women will experience this risk.

Objectives: The aim of our work is to describe the initial bone status and after one year of follow-up in patients starting an anti-aromatase.

Methods: Three hundred and twenty seven (327) patients were recruited from the oncology department of Tizi Ouzou University Hospital, 292 patients were analysed in the initial phase of the study and only 250 patients were evaluated at one year. Of these patients, 157 non-osteoporosis patients received calcium and vitamin d-related health care and 93 patients were osteoporotic and treated with calcium and vitamin D bisphosphonates.- Inclusion criteria:Women with oestrogen receptor breast cancer Treatment with anti-aromatase indicated: a- Immediately after conventional breast treatment $b$ - Tamoxifen relay- Criteria for noninclusion: Bone metastases

Methods: Clinical evaluation: screener risk factors for osteoporosis and fractures. Biological Evaluation: Calcium, Phosphoremia, 25 Hydroxy Vitamin D. Radiological assessment: chest radiograph (profile) or IVA (vertebral fracture assessment) looking for vertebral fracturesLumbar and femoral bone densitometry (HOLOGIC QDR)

Results: The mean age of the patients is $56.8 \pm 7.3$ years, mean body mass index is $27.4 \pm 2.8 \mathrm{~kg} / \mathrm{m} 2.48 \%$ of patients received chemotherapy. The anti-aromatases were given as follows: Anastrozole in $64 \%$, Letrozole in $14 \%$ and Exemestane in $11 \%$. At baseline assessment $n=292,31.6 \%$ of patients had densitometric osteoporosis (T score $<-2$ ) in the lumbar spine and $9.5 \%$ in the femoral neck. 37 patients have a history of peripheral fracture. Six patients have at least one vertebral fracture. The average level of vitamin $D$ is $15.2 \pm 3.5 \mathrm{ng} / \mathrm{L}^{6-29} 283$ patients or $97 \%$ have a deficiency in vit $D(<30 \mathrm{ng} / \mathrm{L})$. After one year of follow-up, patients without osteoporosis ( $n=157)$, annual bone loss is $1.5 \%$ at the lumbar spine and $1.24 \%$ at the hip. 16 patients became osteoporotic. Four patients developed a new vertebral fracture. The one-year follow-up result in osteoporotic patients treated with bisphosphonates with calcium and vitamin $D(n=93)$ had stable bone mineral density $(0.3 \%$ non-significant bone loss). $57 \%$ of patients still have vitamin $D$ insufficiency and two patients had a new vertebral fracture.

Conclusions: Antiaromatases lead to an increased risk of osteoporosis. It is important to evaluate the fracture risk of breast cancer patients through a rheumatology consultation to find all the risk factors, to detect frequent calcium and vita$\min \mathrm{D}$ deficiencies and to treat osteoporosis.

Disclosure of Interest: None declared

DOI: 10.1136/annrheumdis-2018-eular.5557

\section{$\mathrm{AB} 1007$ \\ SEASONAL VARIATIONS OF 25-HYDROXYVITAMIN D3 LEVELS AND ITS RELATION TO PARATHYROID HORMONE LEVELS}

\section{M.A. Teran Tinedo, P. Cristina. HOSPITAL RAMON Y CAJAL, MADRID, Spain}

Objectives: To analyse the relationship between 25-hydroxyvitamin-D3 and parathyroid hormone levels and to determine its variation between the different seasons of the year.

Methods: An observational descriptive study was carried out, collecting and analysing 25-hydroxyvitamin-D3 (25OH-D3) and parathyroid hormone (PTH) serum levels of patients from. January to December of 2017 The frequencies distribution analysis of both variables was compared and Pearson's correlation coefficient (PCC) was used to analyse linear relationship between them. The results were classified by date in four seasons: winter, spring, summer, and autumn, assessing the mean seasonal oscillations of each variable and calculating correlation in each case Different levels of $25 \mathrm{OH}-\mathrm{D} 3$ were evaluated in order to identify differences in the grade of correlation.

Results: Serum samples from 6265 patients were recollected. $59 \%$ of the patients had $25 \mathrm{OH}-\mathrm{D} 3$ levels lower than $25 \mathrm{ng} / \mathrm{ml}$. Pearson's correlation coefficient between both variables was $-0.159(p<0.01)$. The mean values of $250 H-D 3$ were calculated for each seasonal period, establishing a mean level of $23 \mathrm{ng} / \mathrm{ml}$ for winter, $25 \mathrm{ng} / \mathrm{ml}$ for spring, $31 \mathrm{ng} / \mathrm{ml}$ for summer and $29 \mathrm{ng} / \mathrm{ml}$ for autumn. Regarding PTH levels, the mean values for each season were $108 \mathrm{pg} / \mathrm{ml}, 101 \mathrm{pg}$ $\mathrm{ml}, 86 \mathrm{pg} / \mathrm{ml}$ and $84 \mathrm{pg} / \mathrm{ml}$ from winter to autumn respectively. PTH/Vitamin D correlation was also assessed for each period: Pearson's correlation coefficient during winter was $-0.08(p<0.01)$, for spring $-0.249(p<0.01)$, for summer $-0,21$ $(p<0.01)$ and for autumn $-0,19(p<0.01)$. At last, correlation calculated with deficiency levels of $25 \mathrm{OH}-\mathrm{D} 3(<30 \mathrm{ng} / \mathrm{ml})$ was $-0.18(\mathrm{p}<0.01)$, and with levels inferior than $10 \mathrm{ng} / \mathrm{ml}$ was $-0.12(\mathrm{p}<0.01)$.

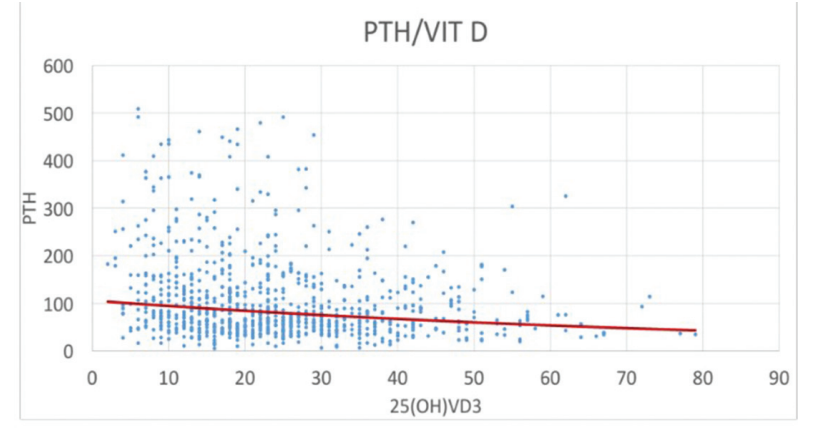

Abstract AB1007 - Figure 1

Conclusions: Linear correlation between levels of $25 \mathrm{OH}-\mathrm{D} 3$ and PTH could not be established in our study, not even using levels classified as vitamin $D$ deficiency. 25OH-D3 levels tended to increase from winter to summer whereas PTH levels decreased inversely during these seasons, without any linear correlation. Disclosure of Interest: None declared DOI: 10.1136/annrheumdis-2018-eular.3908

\section{AB1008 COMPARISON OF BONE MINERAL DENSITY BETWEEN RHEUMATOID ARTHRITIS PATIENTS AND HEALTHY INDIVIDUALS OVER SEVEN YEARS FROM THE TOMORROW STUDY}

M. Tada ${ }^{1}$, K. Inui ${ }^{2}$, Y. Sugioka ${ }^{3}$, T. Okano ${ }^{2}$, Y. Yamada ${ }^{2}$, K. Mandai $^{2}$, K. Mamoto $^{2}$, T. Koike ${ }^{3}$, H. Nakamura ${ }^{2}{ }^{1}$ Orthopaedic Surgery, Osaka City General Hospital; ${ }^{2}$ Orthopaedic Surgery; ${ }^{3}$ Center of Senile Degenerative Disorders, Osaka City University Graduate School of Medicine, Osaka, Japan

Background: Despite advances in treatment, rheumatoid arthritis (RA) remains a key cause of secondary osteoporosis and is also a risk factor for fragility fracture. We have previously reported that bone mineral density (BMD) was lower in patients with RA than in healthy individuals $(\mathrm{HI})$ and examined changes in BMD over 3 years ${ }^{1}$

Objectives: To observe BMD changes over 7 years and identify factors that affect BMD changes in patients with RA.

Methods: We analysed data from the TOMORROW study (UMIN000003876), a prospective cohort for patients with RA and age- and sex-matched HI. BMD was measured at three parts (whole body, lower limb, lumbar spine) using dual-energy $\mathrm{X}$-ray absorptiometry (DXA). We compared the percentage change in BMD $(\% \Delta$ $\mathrm{BMD}$ ) at the three parts in RA and $\mathrm{HI}$ from 2010 to 2017 . Factors affecting $\% \Delta B M D$ in RA were analysed. 